\title{
Construction of a nomogram to predict overall survival for patients with lung large cell neuroendocrine carcinoma: analysis of the SEER database
}

\section{Dong Han}

Beijing Hospital of Traditional Chinese Medicine

\section{Fei Gao}

Chongqing City Hospital of Traditional Chinese Medicine

Nan Li

China Academy of Chinese Medical Science

Hao Wang

Beijing Hospital of Traditional Chinese Medicine

Qi Fu ( $\square$ fuqizyyy@163.com )

\section{Research article}

Keywords: Lung large cell neuroendocrine carcinoma (L-LCNEC), nomogram, Overall survival, SEER

Posted Date: March 5th, 2020

DOI: https://doi.org/10.21203/rs.3.rs-16158/v1

License: (c) (i) This work is licensed under a Creative Commons Attribution 4.0 International License. Read Full License 


\section{Abstract}

Background Lung large cell neuroendocrine carcinoma (L-LCNEC) has a poor prognosis with lower survival rate than other NSCLC patients. The estimation of an individual survival rate is puzzling. The main purpose of this study was to establish a more accurate model to predict the prognosis of L-LCNEC.

Methods Patients aged 18 years or older with L-LCNEC were identified from the Surveillance, Epidemiology and End Results (SEER) database from 2004 to 2015. Cox regression analysis was used to identify factors associated with survival time. The results were used to construct a nomogram to predict 1-year, and 3-year survival probability in L-LCNEC patients. Overall survival (OS) were compared between low risk group and high risk group by the Kaplan-Meier analysis.

Results A total of 3216 patients were included in the study. We randomly divided all included patients into 7:3 training and validating groups. In multivariable analysis of training cohort, age at diagnosis, sex, stage of tumor, surgical treatment, radiotherapy and chemotherapy were independent prognostic factors for OS. All these factors were incorporated to construct a nomogram, which was tested in the validating cohort.

Conclusions we constructed a visual nomogram prognosis model, which had the potential to predict the 1-year and 3-year survival rate of L-LCNEC patients, and could be used as an assistant prediction tool in clinical practice.

\section{Introduction}

Lung cancer is one of the malignant tumors with high incidence and mortality rate in the world [1]. Lung large cell neuroendocrine carcinoma (L-LCNEC) is a kind of rare and invasive non-small cell lung cancer. L-LCNEC, which is characterized by both morphological differentiation of neuroendocrine tumors and large cell lung cancer, belongs to highly malignant neuroendocrine tumor. L-LCNEC is reclassified into the category of neuroendocrine tumors(NETs) by 2015 World Health Organization Classification of Lung Tumors. L-LCNEC is identified as an independent solid tumor with clinical and biological characteristics similar to small cell lung cancers (SCLC) [2]. The incidence of L-LCNEC accounts for $15 \%$ of lung NET and $2.0 \%-3.5 \%$ of the lung cancer resected cases $[3,4]$.

Compared with other NSCLC histological types, L-LCNEC has a poor prognosis with lower survival rate than other NSCLC patients in the same period, even for patients with early stage disease or received surgery treatment [5-8]. There are several literatures about the prognosis of L-LCNEC, but they often came from small samples retrospective analysis. At present, there is no reliable predictor for the prognosis of L-LCNEC. Meanwhile, the independent prognostic factors of cancer can be screened according to the traditional Kaplan Meier method and cox proportional hazards model, but the survival prediction analysis can't predict the survival of an individual. The existing TNM staging can not fully integrate the clinical prognosis information of patients, so it is necessary to develop a new prognosis 
prediction model which can combined with TNM staging to predict the risk of death more accurately and reliably.

At present, nomogram model has been widely used in tumor survival prediction research $[9,10]$. Compared with the traditional TNM staging, nomogram has integrated more individual characteristics, including personal information, disease stage, treatment method, etc., and it has gradually become a new type of prognosis evaluation tool [11-13]. Our large-scale, population-based prospective cohort study is the first attempt to establish a predictive nomogram for L-LCNEC for 1-year and 3-year survival probability.

\section{Methods}

\section{Data Sources}

The data of this retrospective study came from Surveillance, Epidemiology and End Results database (SEER database), which is the authoritative cancer statistical database in the United States. SEER database records the incidence, mortality and disease status of millions of cancer patients. At present, the number of registration stations has been expanded to eighteen. Data from registries are submitted to $\mathrm{NCl}$ twice a year for classification, statistics and aggregation, and cancer information of the population covered is disseminated to the United States and the world. We obtained the clinical information of patients diagnosed as L-LCNEC from SEER database in 2004-2015 with reference number 14026nov2018 using SEER*STAT 8.3.6 software.

\section{Inclusion and exclusion criteria}

We extracted the data of L-LCNEC patients registered from 2004 to 2015. Patients who met the following criteria were included in this study: (1) Adults aged 18 years or older; (2) Patients with pathologically confirmed L-LCNEC; (3) No history of other primary tumor.

Patients with the following conditions were excluded from this study: (1) Patients with incomplete TNM stage (AJCC, 6th Edition) information registration required by the research; (2) Patients whose survival time was less than one month.

Variables extracted from the SEER database included the following: Age at diagnosis, Year of diagnosis, Sex, Race recode, Marital status, Primary Site(Mainbronchus, Upper lobe, Middle lobe, Lower lobe, Overlapping lesion of lung) ,TNM stage, Grade, Surgical recode, Radiation recode, Chemotherapy recode, Survival months, Vital status recode.

\section{Statistical analysis}

We randomly divided all included patients into 7:3 training and validating groups. Multivariable Cox proportional hazards models were determined to evaluate independent prognostic factors in training groups. Multivariable Cox proportional hazards model was used to estimate theßregression coefficient for each of the selected prognostic predictors. The risk scores of the training cohort were generated by 
combining with $\beta$ expression coefficient and individual information of each patient. Those whose riskscore higher than median value were defined as high-risk group, Those whose riskscore lower than or equal to the median value were classified as low-risk group.

Nomogram prediction model was built to predict the prognosis of L-LCNEC patients individually. C-index and calibration curve were used to evaluate the accuracy of model. Predictive value of model was assessed with the area under the receive operator characteristic curve (AUROC) .

The model is validated by validating groups. For better analysis, all variables are converted to categorical variables. Overall survival was defined as the time from the beginning of the diagnosis until death of any cause or until the last follow-up date. The survival analysis was performed using Kaplan-Meier curves with $P$ value determined by Log-rank method. The Hazard's ratio was determined by univariate and multivariate Cox proportional hazard model. All statistical tests were two-sided, and $P$-value $<0.05$ was considered statistically significant. Univariate and multivariate Cox analysis were carried out using SPSS 19.0 software, other statistical analysis were conducted using R(version 3.6.0).

\section{Results}

\section{Characteristics of patients}

According to the inclusion criteria, 3216 patients were included in this study. The average age at diagnosis was $66.17 \pm 10.45$ years old. The median age was 67 years old (age ranging from 18 to 94), 1725 patients were males and 1491 patients were females, the ratio of males to females was 1.16:1. We randomly divided all included patients into 7:3 training and validating groups. 2252 patients were in the training cohort and 964 were in the validation cohort. The characteristics and treatment measures of patients are shown in Table 1.

\section{Independent prognostic factors in the training cohort}

In the training cohort, the clinical characteristics and treatment measures of patients were included in the univariable analysis to explore the factors that may influence overall survival(OS). All significant factors in the univariable analysis and the variables that may be related to OS were entered into the multivariable analysis based on the Cox regression. Multivariate analyses indicated that age at diagnosis, sex, stage of tumor, surgical treatment, radiotherapy and chemotherapy were independent prognostic factors for OS. The univariable and multivariate analysis are shown in Table 2.

\section{Riskscore and survival state in the training cohort}

In the training cohort, there were 1143 low-risk groups and 1109 high-risk groups. The riskscore and survival status of low-risk groups and high-risk groups are shown in Figure 1A and Figure 1B. By the end of follow-up, the survival rate of low-risk group was $39.1 \%$, while that of high-risk group was $9.5 \%$. The median survival time of high-risk group was significantly shorter than low-risk group. (7 months vs 28 months, $p=0.000$, Figure $1 \mathrm{C}$ ). 


\section{Nomogram construction}

Significant independent factors based on the results of the multivariable analysis, including age at diagnosis, sex, stage of tumor, surgical treatment, radiotherapy and chemotherapy were incorporated to establish the nomogram for predicting 1-year, and 3-year survival probability. In the nomogram model, different scores (range 0-100) were given on a points scale at the top of the nomogram by the vertical line of the selected variable. The total score could be accumulated by adding the scores of all variables, and then we could estimate the probability of 1-year and 3-year survival of an individual patient by the vertical line to the prediction line at the bottom of the nomogram(Figure2).

\section{Validation of the Nomogram}

It is demonstrated that Harrell's C-index for the established nomogram to predict OS was 0.75 in the training cohort. Likewise, Harrell's C-index for prediction of OS in the validation cohort was 0.76 .

ROC curve and AUC were used to evaluate the prediction ability of nomogram to patients with L-LCNEC for 1-year survival rate $(A \cup C=0.815)$ and 3-year survival rate $(A \cup C=0.838)$ in the training cohort(Figure $3 \mathrm{~A}, 3 \mathrm{~B})$. In the validation cohort, it also showed a good prediction ability of 1-year survival rate (AUC $=0.812)$ and 3-year survival rate $(A U C=0.86)$ (Figure 3C, 3D).

\section{Calibration of the Nomogram}

The calibration plots showed a good agreement between the prediction and actual observations for 1year survival and 3--year survival in the training and validation cohorts(Figure4A-4D).

\section{Discussion}

L-LCNEC is a rare subtype of lung cancer classification. According to the existing literature reports, the average age of L-LCNEC was 60 years old, most of those were male [14], which was similar to our results. The survival rate of L-LCNEC greatly varied due to the selected patients' age, tumor stage or treatment difference[15-23]. Clinicians' prediction for the survival probability of L-LCNEC is often based on the large-population study, but the estimation of an individual survival rate is puzzling. Therefore, it is necessary to establish a more accurate model to predict the prognosis of L-LCNEC and provide more effective treatment measures for individuals. Based on a retrospective study of high-quality, populationbased data, our study summarized the clinical characteristics of patients with L-LCNEC, analyzed the factors related to the prognosis and established a more reasonable and effective nomogram model for predicting survival rate of L-LCNEC.

Our results indicated that the independent factors influencing the prognosis of L-LCNEC were age at diagnosis, sex, stage of tumor, surgical treatment, radiotherapy and chemotherapy.

Compared with patients under 60 years old, there was an increased risk of death in patients over 60 years old. Increased risk in elderly groups may be due to their poor physical function, intolerance or insensitivity 
to surgery, chemotherapy, radiotherapy or other treatment methods, as well as multiple diseases combination. In terms of gender, the prognosis of male patients was worse than female patients, which may be related to the factors such as more smoking phenomenon involved in male patients or their different body functions or characteristics from female. Similar to other tumors, TNM staging is an independent factor for the prognosis of L-LCNEC patients. Compared with stage I patients, the risk of death in stage II patients increased by 1.06 times, stage III patients increased by 1.35 times, and stage IV patients increased by 3.02 times, thus suggesting that with the tumor staging increase, the risk of death in patients also increased. The possible reason is that the patients' body function is worse and the more complications appear with the advanced tumor stage, they are unable to receive comprehensive treatment for tumors.

There is no standard treatment method for L-LCNEC. Similar to other subtypes of lung cancer, combined therapy, including surgery, chemotherapy and radiotherapy, were taken. The beneficial effect of surgery on L-LCNEC patients has been reported in the previous literatures[24, 25]. Surgical-predominant therapy should be the principle method for treating L-LCNEC patients with early stage presently. Our study indicated surgery was an independent factor affecting the prognosis of L-LCNEC. However, the effect of surgery on the prognosis of L-LCNEC patients was also related to the surgical method. Compared with the patients who did not undergo surgery treatment, the results showed that the mortality risk of patients received local tumor destruction was reduced by $29.4 \%$, but there was no statistical significance $(P=$ $0.729)$, while the mortality risk of those received sublobar resection, lobectomy and pneumonectomy was reduced by $47.1 \%(P=0.000), 61.3 \%(P=0.000), 61.2 \%(P=0.000)$ respectively. Therefore, surgical treatment may not be limited to stage I L-LCNEC patients, but should be extended to resectable patients after adjuvant chemotherapy. Lobectomy or pneumonectomy could be conducted as soon as possible if the patient's physical condition allowed, because the cancer cells grow rapidly and patients may lose the chance of surgery within a few months.

L-LCNEC is aggressive with high potential to metastasize and is easy to recur after operation, so it is not enough to effectively treat the disease by surgery alone. L-LCNEC patients treated by surgery alone were rarely cured even in the early stage [26], which urges more scholars to consider chemotherapy or radiotherapy $[6,18,27,28]$. Two retrospective analysis showed that compared with the patients with surgery alone, platinum-based neoadjuvant chemotherapy or postoperative adjuvant chemotherapy could prolong the recurrence time of tumor and significantly benefit the long-term survival for the patients with early stage $[29,30]$. Chemotherapy regimens for small cell lung cancer/non-small cell lung cancer were used in L-LCNEC treatment, but most of the data were came from single center, small sample or retrospective studies, and the results were controversial [7, 31, 32]. For patients with advanced L-LCNEC, chemotherapy could significantly improve overall survival [33-36]. Our study also showed that chemotherapy may have a survival advantage. Since SEER database does not contain records of chemotherapy regimens, the topic which chemotherapy is better for L-LCNEC patients was not involved in our study. 
Because of the low incidence, there were a few literatures on radiotherapy for L-LCNEC. Mackley believed that if gross residual disease was present after surgery, adjuvant radiation should be recommended, adjuvant radiotherapy could be beneficial to local control and reduced the risk of local recurrence [37]. Rieber conclued that patients with incomplete resection showed a survival benefit from adjuvant radiotherapy [38]. Our results also supported the prognostic benefits of radiotherapy.

Through the establishment of nomogram, we could predict individualized prognosis according to their scores in order to select an appropriate treatment strategy for individuals.

There were some limitations in our study: this was a retrospective study, our results are inevitable subject to selection bias. In addition, due to the limited clinical factors included in SEER database, this study did not analyze the possible factors related to the prognosis of the disease, such as smoking record, genes status, chemotherapy schemes, ect.. Therefore, it is necessary for a prospective evaluation for the nomogram in clinical application.

\section{Conclusion}

In this study, our analysis indicated that age at diagnosis, sex, stage of tumor, surgical treatment, radiotherapy and chemotherapy were independent prognostic factors for overall survival of L-LCNEC patients. And on this basis, we constructed a visual nomogram prognosis model, which had the potential to predict the 1-year and 3-year survival rate of L-LCNEC patients, and could be used as an assistant prediction tool in clinical practice.

\section{Abbreviations}

\section{L-LCNEC}

Lung large cell neuroendocrine carcinoma;

NETs

neuroendocrine tumors;

SEER

The Surveillance, Epidemiology and End Results;

OS

Overall survival; AJCC:American Joint Committee on Cancer; AUROC

Area under the receive operator characteristic curve

\section{Declarations}

\section{Acknowledgments:}

We would like to give special thanks to the efforts of the SEER tumor registry team. 


\section{Authors' contributions:}

(I) Conception and design: Dong Han, Qi Fu; (II) Data analysis and interpretation: All authors; (III) Manuscript writing: All authors; (IV) Final approval of manuscript: All authors.

\section{Funding:}

The research for this manuscript was not financially supported and none of the authors had any relevant financial relationships.

\section{Availability of data and materials:}

All analyzed data are publicly available at the SEER website (http://www.seer. cancer.gov), and should be requested under the approval of the SEER Program administration.

\section{Ethics approval and consent to participate:}

This study used a general dataset from the Surveillance, Epidemiology, and End Results database built by a public health program, and therefore did not require institutional review board approval.

Consent for publication: Not applicable.

\section{Competing interests:}

The authors declare that they have no competing interests.

\section{Author details}

1. Department of Oncology \& Hematology, Beijing Hospital of Traditional Chinese Medicine, Capital Medical University, Beijing, China;

2. Graduate School, China Academy of Chinese Medical Sciences, Beijing, China

\section{References}

1. Torre LA, Bray F, Siegel RL, et al. Global cancer statistics, 2012. CA Cancer J Clin 2015;65:87-108.

2. Fasano M, Della Corte CM, Papaccio F, et al. Pulmonary Large-Cell Neuroendocrine Carcinoma: From Epidemiology to Therapy. J Thorac Oncol 2015;10:1133-41.

3. Travis WD. Advances in neuroendocrine lung tumors. Ann Oncol 2010;21 Suppl 7:vii65-71.

4. Gridelli C, Rossi A, Airoma G, et al. Treatment of pulmonary neuroendocrine tumours: state of the art and future developments. Cancer Treat Rev 2013;39:466-72. 
5. Battafarano RJ, Fernandez FG, Ritter J, et al. Large cell neuroendocrine carcinoma: an aggressive form of non-small cell lung cancer. J Thorac Cardiovasc Surg 2005;130:166-72.

6. Sarkaria IS, lyoda A, Roh MS, et al. Neoadjuvant and adjuvant chemotherapy in resected pulmonary large cell neuroendocrine carcinomas: a single institution experience. Ann Thorac Surg 2011;92:1180-6; discussion 6-7.

7. Naidoo J, Santos-Zabala ML, lyriboz T, et al. Large Cell Neuroendocrine Carcinoma of the Lung: ClinicoPathologic Features, Treatment, and Outcomes. Clin Lung Cancer 2016;17:e121-e9.

8. Filosso PL, Guerrera F, Evangelista A, et al. Adjuvant chemotherapy for large-cell neuroendocrine lung carcinoma: results from the European Society for Thoracic Surgeons Lung Neuroendocrine Tumours Retrospective Database. Eur J Cardiothorac Surg 2017;52:339-45.

9. Karakiewicz PI, Briganti A, Chun FK, et al. Multi-institutional validation of a new renal cancer-specific survival nomogram. J Clin Oncol 2007;25:1316-22.

10. Tang XR, Li YQ, Liang SB, et al. Development and validation of a gene expression-based signature to predict distant metastasis in locoregionally advanced nasopharyngeal carcinoma: a retrospective, multicentre, cohort study. Lancet Oncol 2018;19:382-93.

11. Mariani L, Miceli R, Kattan MW, et al. Validation and adaptation of a nomogram for predicting the survival of patients with extremity soft tissue sarcoma using a three-grade system. Cancer 2005;103:4028.

12. Sternberg $\mathrm{CN}$. Are nomograms better than currently available stage groupings for bladder cancer? J Clin Oncol 2006;24:3819-20.

13. Wang L, Hricak H, Kattan MW, et al. Prediction of organ-confined prostate cancer: incremental value of MR imaging and MR spectroscopic imaging to staging nomograms. Radiology 2006;238:597-603.

14. Sanchez de Cos Escuin J. Diagnosis and treatment of neuroendocrine lung tumors. Arch Bronconeumol 2014;50:392-6.

15. Iyoda A, Hiroshima K, Moriya Y, et al. Postoperative recurrence and the role of adjuvant chemotherapy in patients with pulmonary large-cell neuroendocrine carcinoma. J Thorac Cardiovasc Surg 2009;138:446-53.

16. Glisson BS, Moran CA. Large-cell neuroendocrine carcinoma: controversies in diagnosis and treatment. J Natl Compr Canc Netw 2011;9:1122-9.

17. Varlotto JM, Medford-Davis LN, Recht A, et al. Should large cell neuroendocrine lung carcinoma be classified and treated as a small cell lung cancer or with other large cell carcinomas? J Thorac Oncol $2011 ; 6: 1050-8$. 
18. Fournel L, Falcoz PE, Alifano M, et al. Surgical management of pulmonary large cell neuroendocrine carcinomas: a 10-year experience. Eur J Cardiothorac Surg 2013;43:111-4.

19. Iyoda A, Jiang SX, Travis WD, et al. Clinicopathological features and the impact of the new TNM classification of malignant tumors in patients with pulmonary large cell neuroendocrine carcinoma. Mol Clin Oncol 2013;1:437-43.

20. Filosso PL, Ruffini E, Di Gangi S, et al. Prognostic factors in neuroendocrine tumours of the lung: a single-centre experience. Eur J Cardiothorac Surg 2014;45:521-6; discussion 6.

21. Sakurai $\mathrm{H}$, Asamura $\mathrm{H}$. Large-cell neuroendocrine carcinoma of the lung: surgical management. Thorac Surg Clin 2014;24:305-11.

22. Eichhorn F, Dienemann H, Muley T, et al. Predictors of survival after operation among patients with large cell neuroendocrine carcinoma of the lung. Ann Thorac Surg 2015;99:983-9.

23. Filosso PL, Rena O, Guerrera F, et al. Clinical management of atypical carcinoid and large-cell neuroendocrine carcinoma: a multicentre study on behalf of the European Association of Thoracic Surgeons (ESTS) Neuroendocrine Tumours of the Lung Working Groupdagger. Eur J Cardiothorac Surg 2015;48:55-64.

24. Roesel C, Terjung S, Weinreich G, et al. A Single-Institution Analysis of the Surgical Management of Pulmonary Large Cell Neuroendocrine Carcinomas. Ann Thorac Surg 2016;101:1909-14.

25. Mochizuki E, Matsuura S, Oishi K, et al. Surgical resection for clinical stage I high-grade neuroendocrine carcinoma of the lung. World J Surg Oncol 2018;16:33.

26. Saji H, Tsuboi M, Matsubayashi J, et al. Clinical response of large cell neuroendocrine carcinoma of the lung to perioperative adjuvant chemotherapy. Anticancer Drugs 2010;21:89-93.

27. Veronesi G, Morandi U, Alloisio M, et al. Large cell neuroendocrine carcinoma of the lung: a retrospective analysis of 144 surgical cases. Lung Cancer 2006;53:111-5.

28. Kim KW, Kim HK, Kim J, et al. Outcomes of Curative-Intent Surgery and Adjuvant Treatment for Pulmonary Large Cell Neuroendocrine Carcinoma. World J Surg 2017;41:1820-7.

29. lyoda A, Hiroshima K, Toyozaki T, et al. Adjuvant chemotherapy for large cell carcinoma with neuroendocrine features. Cancer 2001;92:1108-12.

30. Kujtan L, Muthukumar V, Kennedy KF, et al. The Role of Systemic Therapy in the Management of Stage I Large Cell Neuroendocrine Carcinoma of the Lung. J Thorac Oncol 2018;13:707-14.

31. Sun JM, Ahn MJ, Ahn JS, et al. Chemotherapy for pulmonary large cell neuroendocrine carcinoma: similar to that for small cell lung cancer or non-small cell lung cancer? Lung Cancer 2012;77:365-70. 
32. Derks JL, van Suylen RJ, Thunnissen E, et al. Chemotherapy for pulmonary large cell neuroendocrine carcinomas: does the regimen matter? Eur Respir J 2017;49.

33. Shimada Y, Niho S, Ishii G, et al. Clinical features of unresectable high-grade lung neuroendocrine carcinoma diagnosed using biopsy specimens. Lung Cancer 2012;75:368-73.

34. Le Treut J, Sault MC, Lena H, et al. Multicentre phase II study of cisplatin-etoposide chemotherapy for advanced large-cell neuroendocrine lung carcinoma: the GFPC 0302 study. Ann Oncol 2013;24:1548-52.

35. Niho S, Kenmotsu H, Sekine I, et al. Combination chemotherapy with irinotecan and cisplatin for largecell neuroendocrine carcinoma of the lung: a multicenter phase II study. J Thorac Oncol 2013;8:980-4.

36. Tokito T, Kenmotsu H, Watanabe R, et al. Comparison of chemotherapeutic efficacy between LCNEC diagnosed using large specimens and possible LCNEC diagnosed using small biopsy specimens. Int J Clin Oncol 2014;19:63-7.

37. Mackley HB, Videtic GM. Primary carcinoid tumors of the lung: a role for radiotherapy. Oncology (Williston Park) 2006;20:1537-43; discussion 44-5, 49.

38. Rieber J, Schmitt J, Warth A, et al. Outcome and prognostic factors of multimodal therapy for pulmonary large-cell neuroendocrine carcinomas. Eur J Med Res 2015;20:64.

\section{Tables}

Table 1 Demographics and Clinical characteristics of patients 


\begin{tabular}{|c|c|c|c|}
\hline Clinical parameters & $\begin{array}{l}\text { No. of } \\
\text { Patients }\end{array}$ & $\begin{array}{l}\text { No. of } \\
\text { training cohort }\end{array}$ & $\begin{array}{l}\text { No. of } \\
\text { validation cohort }\end{array}$ \\
\hline \multicolumn{4}{|l|}{ Age at diagnosis } \\
\hline$<60$ & $849 \llbracket 26.4 \% \square$ & $601 \square 26.7 \% \square$ & $248 \square 25.7 \% \square$ \\
\hline$\geq 60$ & $2367 \square 73.6 \% \square$ & $1651 \square 73.3 \% \square$ & $716 \square 74.3 \% \square$ \\
\hline \multicolumn{4}{|l|}{ Sex } \\
\hline Male & $1725 \square 53.6 \% \square$ & $1198 \square 53.2 \% \square$ & $527 \square 54.7 \% \square$ \\
\hline Female & $1491 \square 46.4 \% \square$ & $1054 \square 46.8 \% \square$ & $437 \square 45.3 \% \square$ \\
\hline \multicolumn{4}{|l|}{ Race } \\
\hline White & $2702 \square 84.0 \% \square$ & 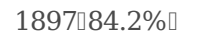 & $805 \square 83.5 \% \square$ \\
\hline Black & $378 \square 11.8 \% \square$ & $262 \square 11.6 \% \square$ & $116 \square 12.0 \% \square$ \\
\hline Other & $136 \square 4.2 \% \square$ & $93 \square 4.1 \% \square$ & $43 \llbracket 4.5 \% \square$ \\
\hline \multicolumn{4}{|l|}{ Marital status at diagnosis } \\
\hline Married & $1722 \square 53.5 \% \square$ & $1178 \square 52.3 \% \square$ & $544 \square 56.4 \% \square$ \\
\hline Non-married & $1494 \square 46.5 \% \square$ & $1974 \square 47.7 \% \square$ & $420 \square 43.6 \% \square$ \\
\hline \multicolumn{4}{|l|}{ Year of diagnosis } \\
\hline 2004 & $174(5.4 \%)$ & $126(5.6 \%)$ & $48(5.0 \%)$ \\
\hline 2005 & $183(5.7 \%)$ & $119(5.3 \%)$ & $64(6.6 \%)$ \\
\hline 2006 & $228(7.1 \%)$ & $164(7.3 \%)$ & $64(6.6 \%)$ \\
\hline 2007 & $242(7.5 \%)$ & $169(7.5 \%)$ & $73(7.6 \%)$ \\
\hline 2008 & $235(7.3 \%)$ & $162(7.2 \%)$ & $73(7.6 \%)$ \\
\hline 2009 & $278(8.6 \%)$ & $196(8.7 \%)$ & $82(8.5 \%)$ \\
\hline 2010 & $294(9.1 \%)$ & $194(8.6 \%)$ & $100(10.4 \%)$ \\
\hline 2011 & $274(8.5 \%)$ & $202(9.0 \%)$ & $72(7.5 \%)$ \\
\hline 2012 & $319(9.9 \%)$ & $232(10.3 \%)$ & $87(9.0 \%)$ \\
\hline 2013 & $347(10.8 \%)$ & $244(10.8 \%)$ & $103(10.7 \%)$ \\
\hline 2014 & $332(10.3 \%)$ & $234(10.4 \%)$ & $98(10.2 \%)$ \\
\hline 2015 & $310(9.6 \%)$ & $210(9.3 \%)$ & $100(10.4 \%)$ \\
\hline \multicolumn{4}{|l|}{ Primary tumor Site } \\
\hline Main bronchus & $117 \square 3.6 \% \square$ & 83ロ3.7\%॰ & $34 \square 3.5 \% \square$ \\
\hline Upper lobe & $1762 \square 54.8 \% \square$ & $1209 \square 53.7 \% \square$ & $553 \square 57.4 \% \square$ \\
\hline Middle lobe & $143 \square 4.4 \square$ & $106 \square 4.7 \% \square$ & $37 \square 3.8 \% \square$ \\
\hline Lower lobe & $773 \llbracket 24.0 \square$ & $567 \square 25.2 \% \square$ & $206 \square 21.4 \% \square$ \\
\hline Overlapping lesion & $37 \square 1.2 \% \square$ & $27 \square 1.2 \% \square$ & $10 \square 1.0 \% \square$ \\
\hline NOS & $384 \square 11.9 \% \square$ & $260 \square 11.5 \% \square$ & $124 \square 12.9 \% \square$ \\
\hline \multicolumn{4}{|l|}{ Grade } \\
\hline Well differentiated & $14 \square 0.4 \% \square$ & $8 \square 0.4 \% \square$ & $6 \square 0.6 \% \square$ \\
\hline Moderately differentiated & $49 \square 1.5 \% \square$ & $35 \square 1.6 \% \square$ & $14 \square 4.5 \% \square$ \\
\hline Poorly differentiated & $1166 \square 36.3 \% \square$ & $825 \square 36.6 \% \square$ & $341 \square 35.4 \% \square$ \\
\hline Undifferentiated; & $386 \square 12.0 \% \square$ & $270 \square 12.0 \% \square$ & $116 \square 12.0 \% \square$ \\
\hline Unknown & $1601 \square 49.8 \% \square$ & $1114 \square 49.5 \% \square$ & $487 \square 50.5 \% \square$ \\
\hline \multicolumn{4}{|l|}{ TNM } \\
\hline I & $903 \llbracket 28.1 \% \square$ & $641 \square 28.5 \% \square$ & $262 \square 27.2 \% \square$ \\
\hline II & $205 \square 6.4 \% \square$ & $145 \square 6.4 \% \square$ & $69 \square 6.2 \% \square$ \\
\hline III & $690 \square 21.5 \% \square$ & $483 \llbracket 21.4 \% \square$ & $207 \square 21.5 \% \square$ \\
\hline IV & $1418 \square 44.1 \% \square$ & $983 \square 43.7 \% \square$ & $435 \square 45.1 \% \square$ \\
\hline \multicolumn{4}{|l|}{ Surgical therapy } \\
\hline No & $1931 \square 60.0 \% \square$ & $1345 \square 59.7 \% \square$ & $586 \square 60.8 \% \square$ \\
\hline Local tumor destruction & $4 \square 0.1 \% \square$ & $2 \square 0.1 \% \square$ & $2 \square 0.2 \% \square$ \\
\hline Less than one lobe resection & $325 \square 10.1 \% \square$ & $235 \square 10.4 \% \square$ & $90 \square 9.3 \% \square$ \\
\hline Lobectomy & $851 \square 26.5 \% \square$ & $595 \square 25.4 \% \square$ & $256 \square 26.6 \% \square$ \\
\hline Pneumonectomy & $105 \square 3.3 \% \square$ & $75 \square 3.3 \% \square$ & $30 \square 3.1 \% \square$ \\
\hline \multicolumn{4}{|l|}{ Radiotherapy } \\
\hline No & $1924 \square 59.8 \% \square$ & $1332 \square 59.1 \% \square$ & $592 \square 61.4 \% \square$ \\
\hline Yes & $1292 \square 40.2 \% \square$ & $920 \square 40.9 \% \square$ & $372 \llbracket 38.6 \& \square$ \\
\hline \multicolumn{4}{|l|}{ Chemotherapy } \\
\hline No & $1453 \square 45.2 \% \square$ & $1022 \square 45.4 \% \square$ & $431 \square 44.7 \% \square$ \\
\hline Yes & $1763 \square 54.8 \% \square$ & $1230 \square 54.6 \% \square$ & 533ロ55.3\%ロ \\
\hline
\end{tabular}

Table2 Univariable analysis and Multivariable analysis of Training Cohort 


\begin{tabular}{|c|c|c|c|c|c|c|}
\hline \multirow[t]{2}{*}{ Parameters } & \multicolumn{3}{|c|}{ Univariable analysis } & \multicolumn{3}{|c|}{ Multivariable analysis } \\
\hline & $\mathrm{HR}$ & $95 \% \mathrm{CI}$ & $P$ & HR & $95 \% \mathrm{CI}$ & $P$ \\
\hline \multicolumn{7}{|l|}{ Age at diagnosis } \\
\hline$<60$ & $1.00 \square \operatorname{Ref} \square$ & & & $1.00 \square \operatorname{Ref} \square$ & & \\
\hline$\geq 60$ & 1.359 & $1.216-1.519$ & 0.000 & 1.407 & $1.253-1.579$ & 0.000 \\
\hline \multicolumn{7}{|l|}{ Sex } \\
\hline Female & $1.00 \square \operatorname{Ref} \square$ & & & $1.00 \square \operatorname{Ref} \square$ & & \\
\hline Male & 0.850 & $0.773-0.936$ & 0.001 & 0.773 & $0.699-0.855$ & 0.000 \\
\hline \multicolumn{7}{|l|}{ Race } \\
\hline Black & $1.00 \llbracket \operatorname{Ref} \square$ & & & $1.00 \square \operatorname{Ref} \square$ & & \\
\hline White & 1.030 & $0.887-1.196$ & 0.698 & 0.953 & $0.817-1.112$ & 0.539 \\
\hline Other & 1.068 & $0.843-1.353$ & 0.586 & 0.991 & $0.779-1.260$ & 0.939 \\
\hline \multicolumn{7}{|l|}{ Marital status at diagnosis } \\
\hline Married & $1.00 \square \operatorname{Ref} \square$ & & & $1.00 \square \operatorname{Ref} \square$ & & \\
\hline Non-married & 1.064 & $0.967-1.171$ & 0.201 & 1.080 & 0.975-1.196 & 0.141 \\
\hline \multicolumn{7}{|l|}{ Year of diagnosis } \\
\hline 2004 & $1.00 \square \mathrm{Ref} \square$ & & & $1.00 \square \operatorname{Ref} \square$ & & \\
\hline 2005 & 1.204 & $0.919-1.577$ & 0.179 & 1.179 & $0.896-1.550$ & 0.240 \\
\hline 2006 & 1.093 & 0.850-1.405 & 0.488 & 1.099 & $0.851-1.417$ & 0.470 \\
\hline 2007 & 1.193 & 0.928-1.533 & 0.169 & 0.956 & $0.740-1.234$ & 0.729 \\
\hline 2008 & 1.073 & $0.830-1.387$ & 0.591 & 0.968 & $0.746-1.256$ & 0.806 \\
\hline 2009 & 1.154 & $0.903-1.477$ & 0.253 & 1.068 & $0.831-1.374$ & 0.606 \\
\hline 2010 & 1.063 & $0.828-1.365$ & 0.633 & 0.968 & $0.750-1.244$ & 0.801 \\
\hline 2011 & 1.285 & $1.003-1.645$ & 0.047 & 1.179 & $0.917-1.516$ & 0.200 \\
\hline 2012 & 1.351 & $1.061-1.720$ & 0.015 & 1.088 & $0.851-1.392$ & 0.500 \\
\hline 2013 & 1.198 & $0.937-1.533$ & 0.149 & 1.073 & $0.836-1.377$ & 0.582 \\
\hline 2014 & 1.429 & $1.109-1.840$ & 0.006 & 1.113 & $0.860-1.441$ & 0.415 \\
\hline 2015 & 1.317 & $0.959-1.810$ & 0.089 & 1.159 & 0.839-1.599 & 0.371 \\
\hline \multicolumn{7}{|l|}{ Primary tumor Site } \\
\hline Main bronchus & $1.00 \llbracket \operatorname{Ref} \square$ & & & $1.00 \llbracket \operatorname{Ref} \square$ & & \\
\hline Upper lobe & 0.450 & $0.355-0.572$ & 0.000 & 0.722 & 0.567-0.919 & 0.008 \\
\hline Middle lobe & 0.511 & $0.374-0.698$ & 0.000 & 0.897 & $0.654-1.232$ & 0.503 \\
\hline Lower lobe & 0.448 & $0.350-0.575$ & 0.000 & 0.746 & $0.579-0.960$ & 0.023 \\
\hline Overlapping lesion & 0.635 & $0.388-1.041$ & 0.072 & 0.740 & $0.449-1.220$ & 0.238 \\
\hline NOS & 0.824 & $0.634-1.071$ & 0.148 & 0.655 & $0.502-0.855$ & 0.002 \\
\hline \multicolumn{7}{|l|}{ Grade } \\
\hline Well differentiated & $1.00 \square \operatorname{Ref} \square$ & & & $1.00 \square \operatorname{Ref} \square$ & & \\
\hline Moderately differentiated & 0.757 & $0.285-2.007$ & 0.575 & 0.933 & $0.349-2.495$ & 0.890 \\
\hline Poorly differentiated & 0.986 & $0.409-2.379$ & 0.975 & 1.127 & $0.464-2.736$ & 0.792 \\
\hline Undifferentiated; & 1.125 & $0.463-2.734$ & 0.749 & 1.279 & $0.523-3.128$ & 0.590 \\
\hline Unknown & 1.592 & $0.661-3.834$ & 0.300 & 1.093 & $0.450-2.651$ & 0.844 \\
\hline \multicolumn{7}{|l|}{ TNM } \\
\hline I & $1.00 \square \operatorname{Ref} \square$ & & & $1.00 \square \operatorname{Ref} \square$ & & \\
\hline II & 1.568 & $1.248-1.971$ & 0.000 & 2.062 & $1.627-2.614$ & 0.000 \\
\hline III & 2.423 & $2.090-2.808$ & 0.000 & 2.357 & $1.950-2.844$ & 0.000 \\
\hline IV & 4.098 & $4.305-5.597$ & 0.000 & 4.021 & $3.329-4.856$ & 0.000 \\
\hline \multicolumn{7}{|l|}{ Surgical therapy } \\
\hline No & $1.00 \square \operatorname{Ref} \square$ & & & $1.00 \square \operatorname{Ref} \square$ & & \\
\hline Local tumor destruction & 0.501 & $0.070-3.559$ & 0.489 & 0.706 & $0.099-5.051$ & 0.729 \\
\hline Less than one lobe resection & 0.361 & $0.305-0.427$ & 0.000 & 0.529 & $0.431-0.651$ & 0.000 \\
\hline Lobectomy & 0.247 & $0.217-0.281$ & 0.000 & 0.387 & $0.322-0.465$ & 0.000 \\
\hline Pneumonectomy & 0.309 & $0.229-0.470$ & 0.000 & 0.388 & $0.281-0.536$ & 0.000 \\
\hline \multicolumn{7}{|l|}{ Radiotherapy } \\
\hline No & $1.00 \square \operatorname{Ref} \square$ & & & $1.00 \square \operatorname{Ref} \square$ & & \\
\hline Yes & 1.413 & $1.283-1.557$ & 0.000 & 0.833 & $0.749-0.928$ & 0.001 \\
\hline
\end{tabular}


No $1.00 \square R$ Ref $\square \quad 1.00 \square R e f \square$

\begin{tabular}{lllllll} 
Yes & 1.112 & $1.010-1.224$ & 0.031 & 0.559 & $0.500-0.624$ & 0.000 \\
\hline
\end{tabular}

\section{Figures}

A

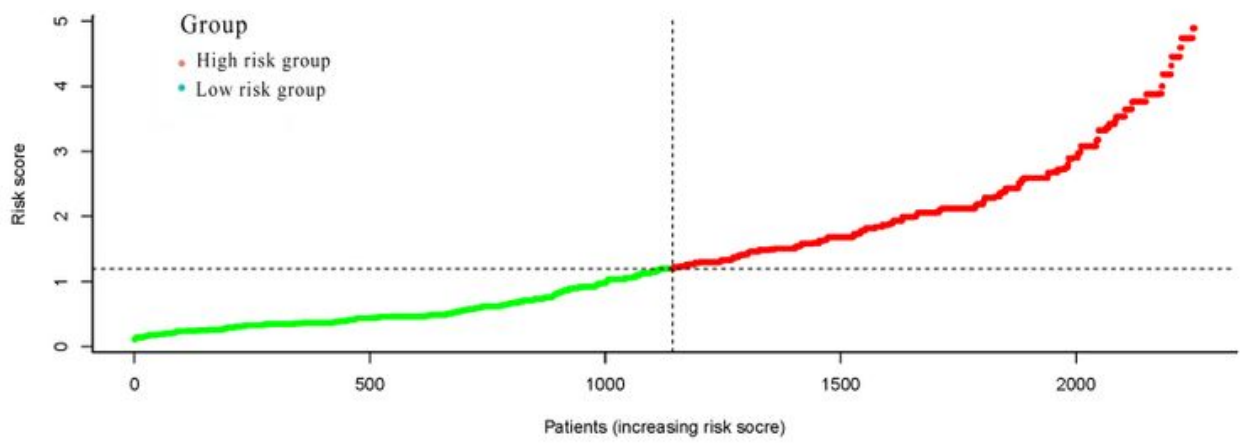

B

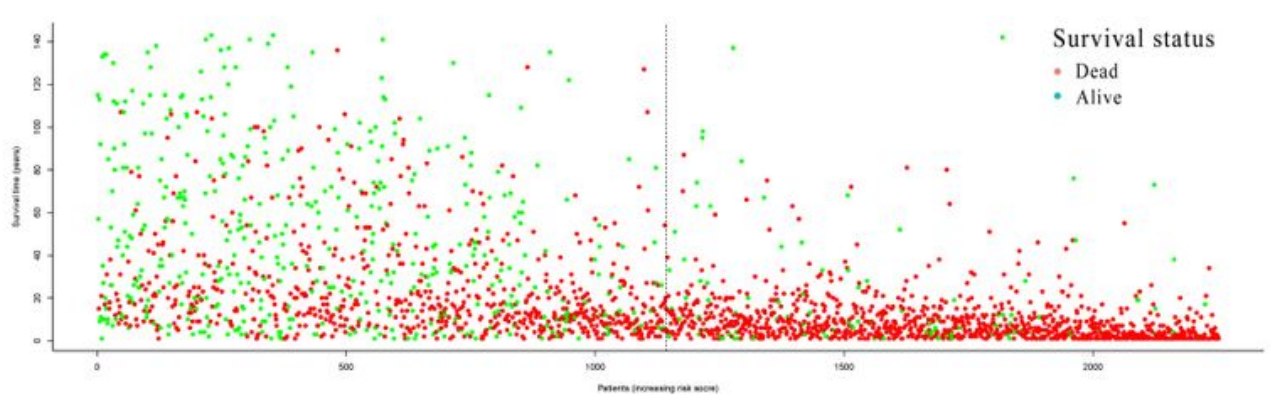

C

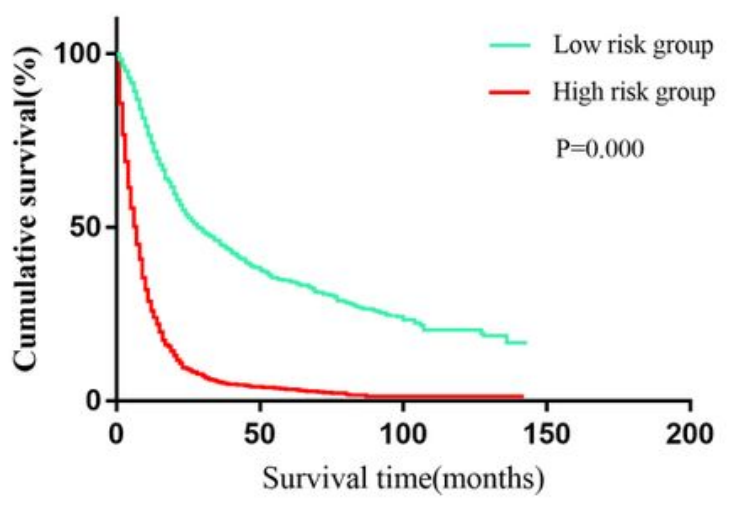

Figure 1 
Figure 1

A: Patients ranked in the order of riskscore in the training cohort. The green line represents low risk groups, the red line represents high risk groups, the horizontal dotted line represents the value of median riskscore, low risk groups and high risk groups are separated by the vertical dotted line. B: The survival status of low risk groups and high risk groups. Low risk groups and high risk groups are separated by the vertical dotted line. Green dots represents survival status, red dots represents dead status. C: Overall survival of patients stratified by riskscore. Overall survival of high-risk group $(n=1109)(H R=3.298$, $95 \% \mathrm{Cl}=2.975-3.657, \mathrm{P}=0.000)$ versus low-risk group $(\mathrm{n}=1143)$.

Points

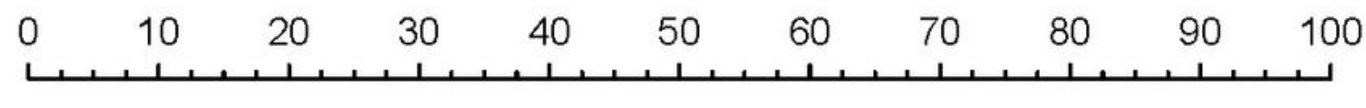

Age

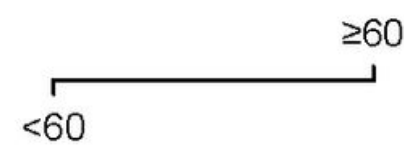

Sex

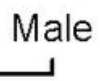

Female

TNM

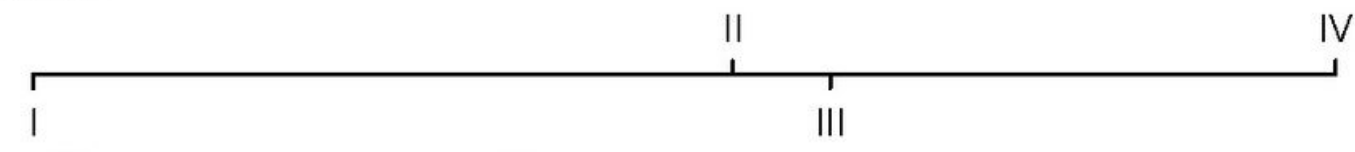

Surgical treatment

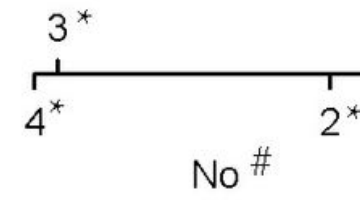

Radiotherapy

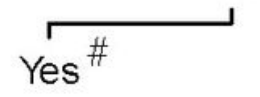

Chemotherapy

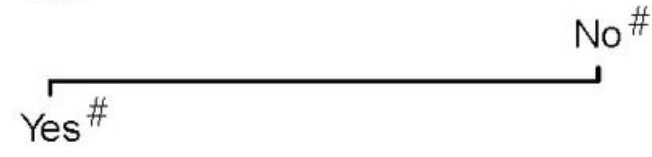

Total Points

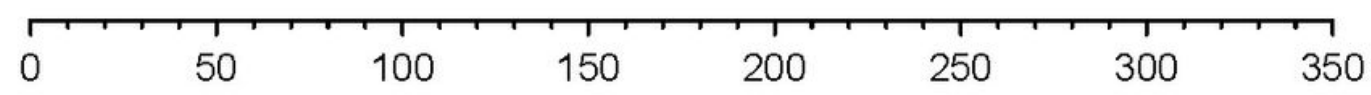

1-Year Survival

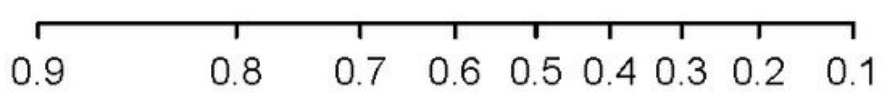

3-Year survival

$\begin{array}{llllllllllll}0.8 & 0.7 & 0.6 & 0.5 & 0.4 & 0.3 & 0.2 & 0.1\end{array}$

Figure 2 
Figure 2

Prognostic nomogram for patients with L-LCNEC. *0: No surgical treatment, 1: Local tumor destruction, 2: sublobar resection, 3: Lobectomy, 4: Pneumonectomy. \#Yes: Received this treatment, No: Not received this treatment
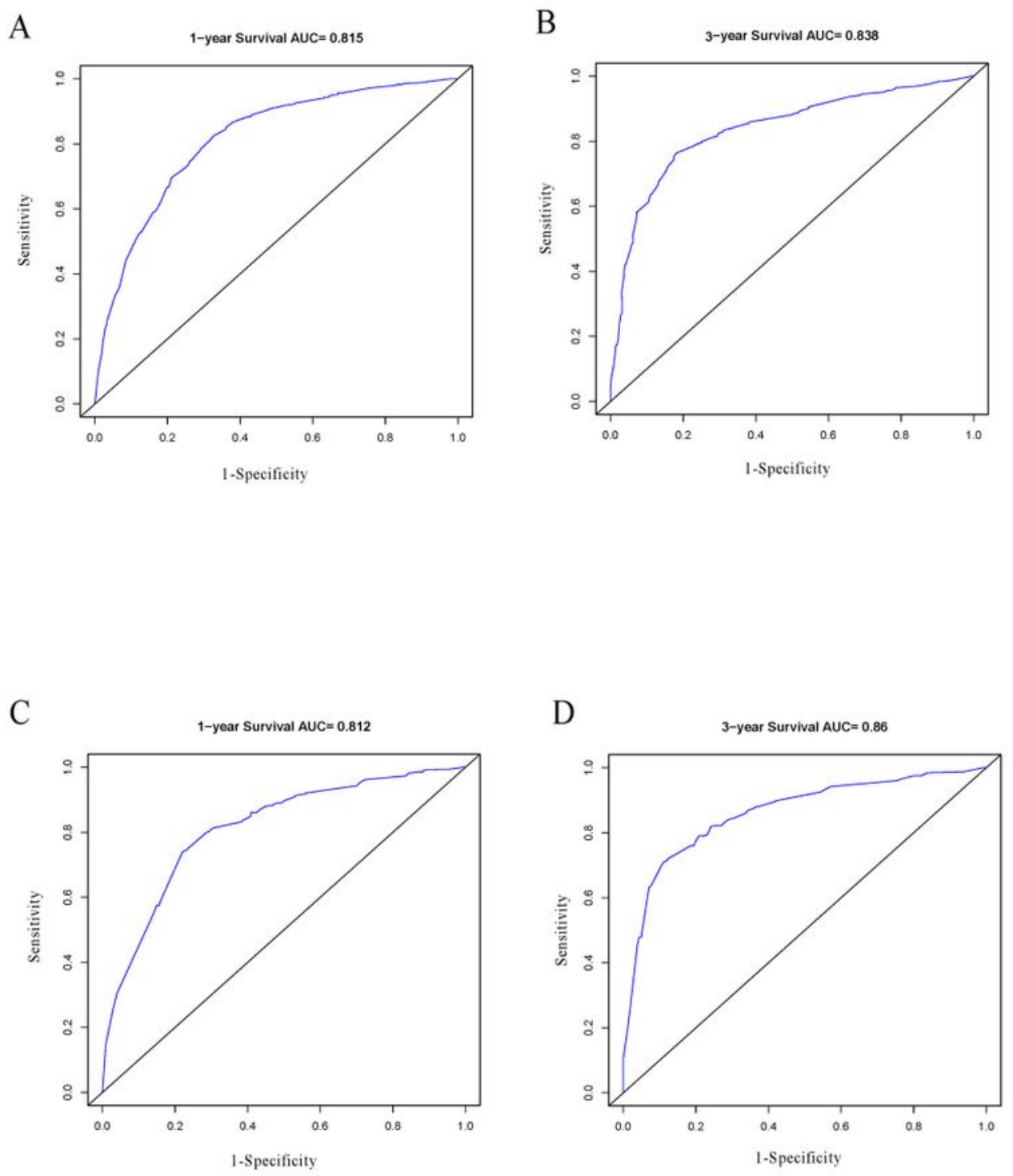

Figure 3

Figure 3 
ROC curve for the prediction ability of nomogram to patients with L-LCNEC for (A) 1-year survival rate, (B) 3-year survival rate in the training cohort and for (C) 1-year survival rate, (D) 3-year survival rate in the validation cohort.

A

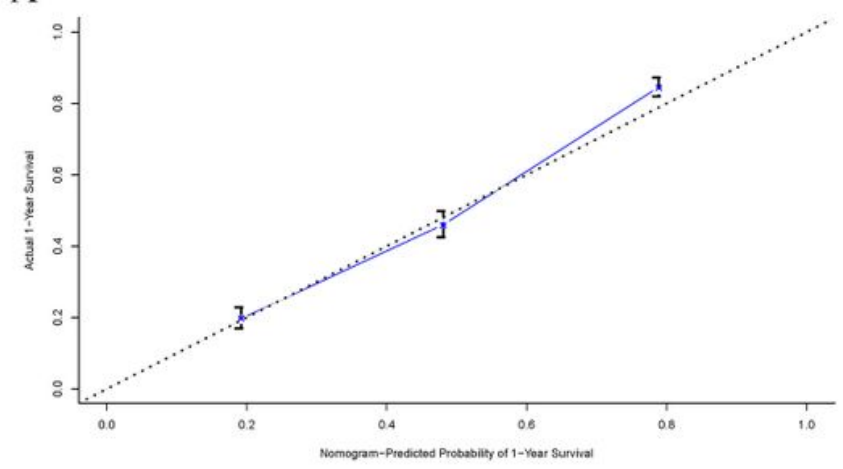

$\mathrm{C}$

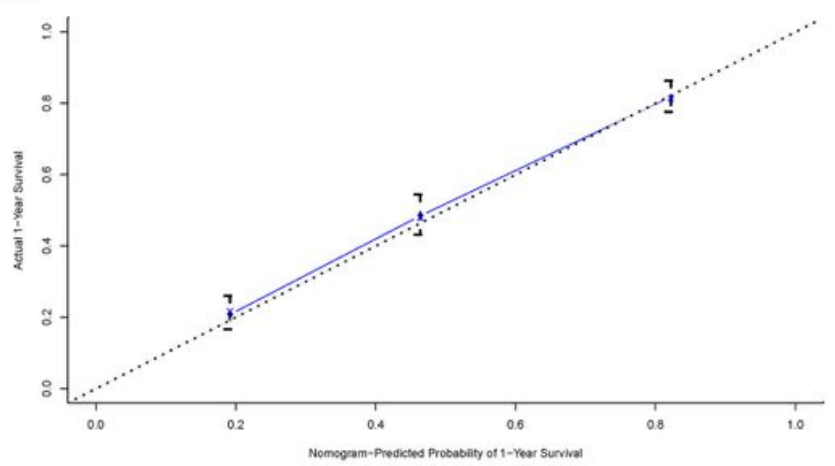

B

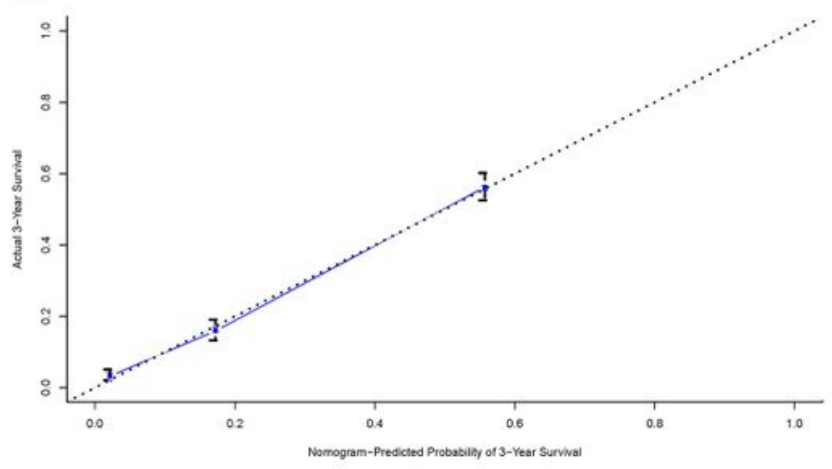

D

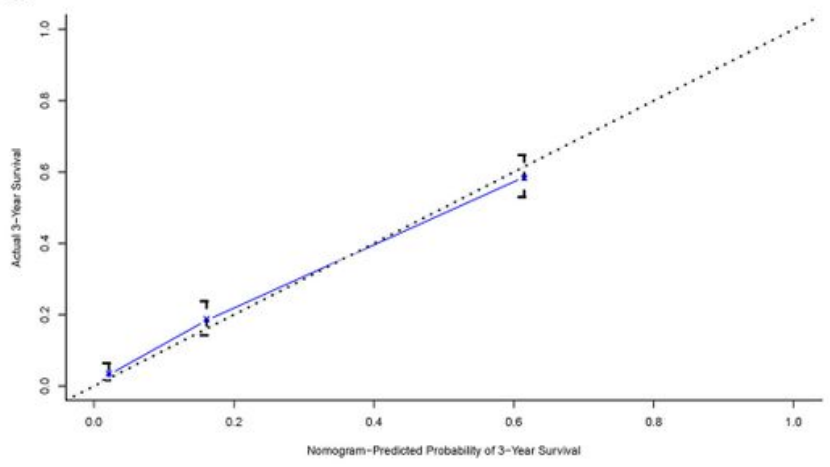

Figure 4

\section{Figure 4}

The calibration curve for predicting patients survival at (A) 1-year, (B)3-year in the training cohort and at (C) 1-year , (D)3-year in the validation cohort. Nomogram-predicted probability of survival is plotted on the $x$-axis, and actual survival is plotted on the $y$-axis. 